\& Research Square

\title{
Tear Film Stability After Primary Pterygium Excision Combined with Limbal Stem Cell Transplantation is Superior to Amniotic Membrane Transplantation: A Meta-Analysis
}

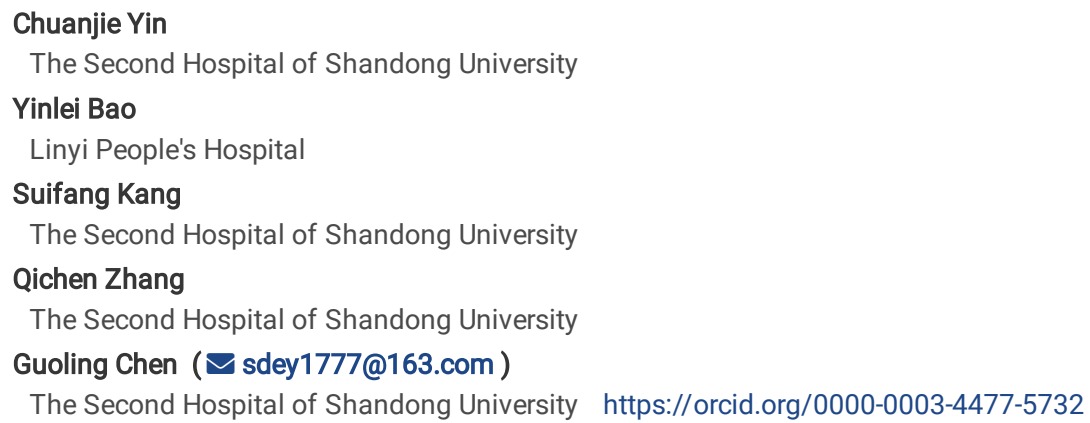




\section{Abstract}

Purpose To evaluate the tear film stability after primary pterygium excision combined with Limbal stem cell transplantation (LSCT) or amniotic membrane transplantation (AMT).

Methods We searched the PubMed, EMBASE, Web of Science, Cochrane Library, CNKI, Wan Fang and VIP databases for all studies on tear film stability after primary pterygium excision combined with LSCT or AMT. The mean difference (MD) and $95 \%$ confidence interval (CI) were calculated for outcomes using the fixed effect or random effect model.

Results Seven studies with a total of 531 eyes were enrolled in our meta-analysis, which revealed that comparison between the LSCT group and the AMT group: Ocular Surface Disease Index (OSDI) 3 months postoperatively (MD =-5.16, 95\%Cl:-6.48,-3.85, $P \otimes 0.05$ ), Tear break-up time (BUT) 1 or 3 months postoperatively ( 1 month: $\mathrm{MD}=0.30,95 \% \mathrm{Cl}:-0.66,1.26, P=0.54 ; 3$ months: $\mathrm{MD}=1.30,95 \% \mathrm{Cl}:-0.13,2.72, P=0.07)$, Schirmer I test 1 or 3 months postoperatively $(1$ month: $\mathrm{MD}=0.05,95 \% \mathrm{Cl}:-0.41,0.51, P=0.82 ; 3$ months: $\mathrm{MD}=1.41,95 \% \mathrm{Cl}: 0.81,2.02, P \otimes 0.05)$, Corneal fluorescein staining (CFS) score 1 month postoperatively $(\mathrm{MD}=-0.49,95 \% \mathrm{Cl}:-1.29,0.31, P=0.23)$.

Conclusion Primary pterygium excision combined with LSCT is associated with better tear film stability changes than AMT.

\section{Introduction}

Pterygium is a wing-shaped fibrovascular growth of the conjunctiva that extends across the limbus and invades the cornea [1]. It is a common ocular surface disease and is extremely common in occurrence and worldwide distribution [2]. The exact pathogenesis of the injury is complex and remains incompletely understood. It is associated with multiple risk factors such as ultraviolet light, age, hereditary factors, chronic inflammation, microtrauma, and heat [3]. Pterygia can affect vision and cause redness, foreign body sensation, decreased tear film stability, and affected patients frequently have dry eye disease (DED) symptoms [4].

The only effective method for the treatment of pterygium is surgery [5]. There are many surgical methods for pterygium. Each of these methods has its pros and cons, and there is no gold standard for pterygium surgery. Common surgical methods for pterygium currently consist of surgical resection of the involved area, followed by its coverage using conjunctiva with limbal stem cells or an amniotic membrane [6]. Limbal stem cells are located in the limbal epithelial layer and are the ultimate source of the transparent corneal epithelium [7, 8]. Amniotic membrane transplantation (AMT) is increasingly used in ophthalmic surgery. It can resist adhesions and is beneficial in promoting epithelialization and inhibiting inflammation and neovascularization [9]. Another advantage of AMT application to the ocular surface is that it is an avascular tissue, which can effectively inhibit neovascularization during corneal surface reconstruction [10]. Limbal stem cell transplantation (LSCT) and AMT can both be used in pterygium surgery.

A stable anterior tear film is essential for ocular health, mainly because it creates a protective and lubricated environment for the tissues of the palpebral bulbar surfaces [11]. Recent studies have demonstrated that pterygium has a close relationship with tear film stability. Although decreased tear film stability has been reported as one of the risk factors for pterygium formation, pterygium itself also contributes to ocular surface instability [12]. Pathological conjunctival, corneal or eyelid changes in pterygium can decrease tear film stability. Patients with pterygium have disturbances in tear quality, quantity, and reduction of conjunctival goblet cell population [3]. One study showed that excision of pterygium could lead to an improved tear film stability [13]. The main objective of this summary of our review is to report the comparison of tear film stability after primary pterygium excision combined with LSCT or AMT based on the best available evidence.

\section{Methods \\ Search Strategy}

We searched the PubMed, EMBASE, Web of Science, Cochrane Library, CNKI, Wan Fang and VIP databases for all studies on tear film stability after primary pterygium excision combined with LSCT or AMT. The Mesh and Entry terms were as follows: ("Tear film" OR "Dry Eye Syndromes") AND ("Pterygium") AND ("Limbal stem cell") AND ("Amnion" OR "Amniotic Membrane") AND ("Transplant" OR “Graft" OR “Transplantation") AND ("randomized controlled trial” OR "randomized" OR "placebo"). The study selection process was shown in Fig. 1. The meta-analysis was performed according to the PRISMA statement and was registered at International Prospective Register of System Reviews (CRD number: 42021265281: www.crd.york.ac.uk/PROSPERO/).

\section{Selection Criteria}

The inclusion criteria were: (1) Type of studies: Randomized controlled trials (RCT); (2) Type of participants: Patients with primary pterygium; (3) Interventions: Pterygium excision combined with LSCT or AMT; (4) Acquisition of at least one of the outcome measures: 1 or 3 months postoperative Ocular Surface Disease Index (OSDI), Tear break-up time (BUT), Schirmer test without anesthesia (Schirmer I test) and Corneal fluorescein staining (CFS) score. (5) Both groups were comparable on outcome measures. Studies would be excluded if they did not meet the inclusion criteria.

\section{Quality Assessment}

Our team authors individually reviewed the risk of selection bias, performance bias, detection bias, attribution bias, reporting bias and other biases of each included study using the Cochrane Risk of Bias Tool. Disagreements were resolved by our team authors by discussion. The risks of bias for 7 studies were 


\section{Data Extraction}

Extracted information and data from the selected studies were as follows: the first author's surname, year of publication, country, study type, sample size, OSDI, BUT, Schirmer I test and CFS score. The outcome measures were continuous data, which we expressed as mean and standard deviation (SD).

\section{Statistical Analysis}

The mean difference (MD) and $95 \%$ confidence interval $(\mathrm{Cl})$ were calculated for outcomes. Heterogeneity was estimated using the Cochrane I square $\left(\mathrm{I}^{2}\right)$ statistics and Q statistics. The fixed effect model was employed when low heterogeneity $\left(I^{2}<50 \%, P>0.1\right)$. The sensitivity analysis was performed when significant heterogeneity $\left(I^{2}>50 \%, P<0.1\right)$ was detected. The random effect model was adopted if heterogeneity could not be eliminated. Publication bias was estimated using Begg's and Egger's tests. A p-value of less than 0.05 was considered statistically significant. All analyses were down with RevMan version 5.3 and Stata version 15.1 software.

\section{Results}

\section{Search Results}

The specific selection process was shown in Fig. 1. Forty-four records were identified through the initial electronic search, of which 23 reports were screened after removing duplicates. Among the remaining studies, 8 were excluded because their titles and abstracts were irrelevant to our study. Then 8 studies were excluded for other reasons: incomplete data reporting or inrigorous experimental design. Finally, 7 studies [14-20] were enrolled in our meta-analysis.

\section{Characteristics of Included Trials}

The 7 studies finally included were published between 2013 and 2020, which provided a large sample size containing 531 eyes. Of these, 7 eligible studies were all conducted in China, which included at least one of the outcome measures: OSDI, BUT, Schirmer I test and CFS score 1 or 3 months postoperatively. The characteristics of all included studies were shown in Table 1. 
Table 1

Main characteristics of all included studies

\begin{tabular}{|c|c|c|c|c|c|c|c|c|c|c|}
\hline \multirow[t]{2}{*}{$\begin{array}{l}\text { First } \\
\text { Author }\end{array}$} & \multirow[t]{2}{*}{ Year } & \multirow[t]{2}{*}{ Country } & \multirow[t]{2}{*}{$\begin{array}{l}\text { Study } \\
\text { Design }\end{array}$} & \multirow{2}{*}{$\begin{array}{l}\text { Sample } \\
\text { size }\end{array}$} & \multirow{2}{*}{$\begin{array}{l}\text { OSDI } \\
3 \text { months } \\
\text { postoperatively }\end{array}$} & \multicolumn{2}{|l|}{ BUT(s) } & \multicolumn{2}{|c|}{ Schirmer I test(mm/5min) } & \multirow{2}{*}{$\begin{array}{l}\text { CFS s } \\
1 \mathrm{~mol} \\
\text { posto }\end{array}$} \\
\hline & & & & & & $\begin{array}{l}1 \text { month } \\
\text { postoperatively }\end{array}$ & $\begin{array}{l}3 \text { months } \\
\text { postoperatively }\end{array}$ & $\begin{array}{l}1 \text { month } \\
\text { postoperatively }\end{array}$ & $\begin{array}{l}3 \text { months } \\
\text { postoperatively }\end{array}$ & \\
\hline Bai & 2017 & China & RCT & $32 / 34$ & - & $\begin{array}{l}\text { LSCT(11.56 } \pm \\
3.82) ; \\
\text { AMT(11.67 } \pm \\
3.52)\end{array}$ & $\begin{array}{l}\text { LSCT(11.98 } \pm \\
4.37) ; \\
\text { AMT(12.01 } \pm \\
3.00)\end{array}$ & $\begin{array}{l}\text { LSCT(11.31 } \pm \\
3.82) ; \\
\text { AMT(12.31 } \pm \\
3.52)\end{array}$ & $\begin{array}{l}\text { LSCT(12.58 } \pm \\
3.37) ; \\
\text { AMT(12.01 } \pm \\
3.07)\end{array}$ & - \\
\hline Chen & 2018 & China & RCT & $50 / 50$ & - & $\begin{array}{l}\text { LSCT(15.52 } \pm \\
0.50) ; \\
\text { AMT'(10.30 } \pm \\
0.51)\end{array}$ & - & $\begin{array}{l}\text { LSCT(14.15 } \pm \\
0.30) ; \\
\text { AMT(13.13 } \pm \\
0.31)\end{array}$ & - & $\begin{array}{l}\text { LSCT } \\
0.13) ; \\
\text { AMT( } \\
0.15)\end{array}$ \\
\hline Dai & 2013 & China & RCT & $20 / 20$ & - & $\begin{array}{l}\text { LSCT }(8.30 \pm \\
1.46) ; \\
\text { AMT }(6.55 \pm \\
1.32)\end{array}$ & 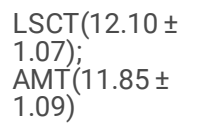 & $\begin{array}{l}\text { LSCT }(12.98 \pm \\
0.85) ; \\
\text { AMT(13.28 } \pm \\
1.16)\end{array}$ & $\begin{array}{l}\text { LSCT(12.58 } \pm \\
0.75) ; \\
\text { AMT(12.93 } \pm \\
1.00)\end{array}$ & $\begin{array}{l}\text { LSCT } \\
0.89) ; \\
\text { AMT( } \\
0.95)\end{array}$ \\
\hline Hai & 2019 & China & RCT & $56 / 50$ & $\begin{array}{l}\text { LSCT(11.43 } \pm \\
5.84) ; \\
\text { AMT(17.52 } \pm \\
6.53)\end{array}$ & $\begin{array}{l}\text { LSCT }(7.63 \pm \\
2.31) ; \\
\text { AMT }(6.82 \pm \\
1.68)\end{array}$ & $\begin{array}{l}\text { LSCT }(12.20 \pm \\
2.73) ; \\
\text { AMT( }(8.92 \pm \\
1.34)\end{array}$ & $\begin{array}{l}\text { LSCT( }(7.27 \pm \\
2.64) ; \\
\text { AMT }(6.75 \pm \\
2.19)\end{array}$ & $\begin{array}{l}\text { LSCT( } 9.68 \pm \\
3.03) ; \\
\text { AMT }(7.85 \pm \\
1.92)\end{array}$ & - \\
\hline $\mathrm{Li}$ & 2020 & China & RCT & $30 / 30$ & $\begin{array}{l}\text { LSCT( } 12.88 \pm \\
2.97) ; A M T(17.63 \\
\pm 3.29)\end{array}$ & - & $\begin{array}{l}\text { LSCT }(12.31 \pm \\
2.24) ; \\
\text { AMT }(8.85 \pm \\
2.03)\end{array}$ & - & $\begin{array}{l}\text { LSCT }(9.82 \pm \\
2.44) ; \\
\text { AMT'(7.96 } \pm \\
2.30)\end{array}$ & - \\
\hline $\mathrm{Li}$ & 2015 & China & $\mathrm{RCT}$ & $28 / 28$ & - & $\begin{array}{l}\text { LSCT(7.00 } \pm \\
1.68) ; \\
\text { AMT'(7.64 } \pm \\
2.34)\end{array}$ & $\begin{array}{l}\text { LSCT(12.64 } \pm \\
2.45) ; \\
\text { AMT(11.61 } \\
2.48)\end{array}$ & $\begin{array}{l}\text { LSCT(12.64 } \pm \\
2.68) ; \\
\text { AMT(11.64 } \\
1.73)\end{array}$ & $\begin{array}{l}\text { LSCT(14.39 } \pm \\
2.67) ; \\
\text { AMT(13.71 } \pm \\
2.39)\end{array}$ & - \\
\hline $\mathrm{Xu}$ & 2014 & China & $\mathrm{RCT}$ & $54 / 49$ & - & $\begin{array}{l}\text { LSCT(11.5 } \pm \\
1.8) ; A M T(12.0 \\
\pm 1.5)\end{array}$ & $\begin{array}{l}\text { LSCT }(11.7 \pm \\
1.2) ; \text { AMT }(12.0 \\
\pm 1.6)\end{array}$ & - & - & - \\
\hline
\end{tabular}

LSCT: Limbal stem cell transplantation; AMT: Amniotic membrane transplantation; OSDI: Ocular Surface Disease Index; BUT: Tear break-up time; CFS: Corne; fluorescein staining; s: seconds; mm: millimeters; min: minutes

\section{Quality Assessment}

Although all studies were performed with randomization, only 2 studies described the randomization method [18, 19]. All trials lacked full description in the aspects: allocation concealment and blind methods. Seven studies were low risk of bias in both incomplete outcome data and selective reporting. A summary of the risk of bias judgments made by the review authors was shown in Fig. 2.

\section{Quantitative Analysis}

\section{OSDI 3 months postoperatively}

Two studies were conducted in the meta-analysis of OSDI outcomes [17, 18]. A total of 86 eyes were randomly allocated to the pterygium excision combined with the LSCT group and 80 to the AMT group. Compared with the AMT group, the OSDI scores were decreased in the LSCT group. The difference was statistically significant (pooled $\mathrm{MD}=-5.16,95 \% \mathrm{Cl}:-6.48,-3.85, P \unrhd 0.05$, fixed effect), with low heterogeneity $\left(I^{2}=0 \%, P=0.597\right)(\mathrm{Fig} .3)$.

\section{BUT 1 month postoperatively}

Data on BUT 1 month postoperatively were obtained from 6 studies [14-17, 19, 20], and the forest plot was shown in Fig. 4 . Pooled data from 240 eyes were randomly allocated to the LSCT group and 231 to the AMT group. The heterogeneity test result showed significant heterogeneity across studies $\left(I^{2}=99 \%\right.$, $P \otimes 0.1$, fixed effect) (Fig. 4a). A sensitivity analysis was conducted for the 6 studies, and it was found that the study of Chen 2018 had a significant effect on the heterogeneity. After this study was removed, the pooled effect size of the meta-analysis varied considerably (Table 2). Therefore, the study of Chen 2018 was removed. The heterogeneity test was performed again, and the result showed that the remaining 5 studies still had high heterogeneity $\left(I^{2}=82 \%, P=0.15\right.$, fixed effect) (Fig. 4b). Finally, the random effect model was adopted for the study. Since the data and results of Chen 2018 were too heterogeneous compared with the results of other studies, it was still excluded. The values of BUT were slightly increased in the LSCT group compared to the AMT group, but there was no statistical difference (pooled $\mathrm{MD}=0.30,95 \% \mathrm{Cl}:-0.66,1.26, P=0.54$, random effect) (Fig. 4c). 
Table 2

The sensitivity analysis of BUT 1 month postoperatively

between the LSCT group and the AMT group

\begin{tabular}{|lll|}
\hline Study omitted & Estimate & [95\% Conf. Interval] \\
\hline Bai 2017 & 4.2349544 & {$[4.0579343,4.4119749]$} \\
\hline Chen 2018 & 0.28535509 & {$[-0.10060638,0.67131656]$} \\
\hline Dai 2013 & 4.2984462 & {$[4.1185079,4.4783845]$} \\
\hline Hai 2019 & 4.382339 & {$[4.2013083,4.5633698]$} \\
\hline Li 2015 & 4.3275676 & {$[4.1489701,4.506165]$} \\
\hline Xu 2014 & 4.5795312 & {$[4.3962579,4.7628045]$} \\
\hline Combined & 4.1921792 & {$[4.0160324,4.368326]$} \\
\hline
\end{tabular}

\section{BUT 3 months postoperatively}

Data on BUT 3 months postoperatively were obtained from 6 studies [14, 16-20], and the forest plot was shown in Fig. 5. Pooled data from 220 eyes were randomly allocated to the LSCT group, and 211 eyes were assigned to the AMT group. According to the heterogeneity test in this study, it was prompted that overall heterogeneity was high $\left(I^{2}=94 \%, P \otimes 0.1\right.$, fixed effect) (Fig. 5a). A sensitivity analysis was conducted for the 6 studies, and it was found that no matter which study was removed, the change of pooled effect size was not significant (Table 3). Therefore, we chose the random effect model for the study. The values of BUT were increased in the LSCT group compared to the AMT group. However, the difference was not significant (pooled MD $=1.30,95 \% \mathrm{Cl}:-0.13,2.72$, $P=0.07$, random effect) (Fig. 5b).

Table 3

The sensitivity analysis of BUT 3 months postoperatively between the LSCT group and the AMT group

\begin{tabular}{|lll|}
\hline Study omitted & Estimate & [95\% Conf. Interval] \\
\hline Bai 2017 & 0.63652331 & {$[0.41863605,0.85441053]$} \\
\hline Dai 2013 & 0.56102991 & {$[0.35146546,0.77059436]$} \\
\hline Hai 2019 & 0.26760724 & {$[0.0440308,0.49118367]$} \\
\hline Li 2020 & 0.38559076 & {$[0.17448317,0.59669834]$} \\
\hline Li 2015 & 0.54535377 & {$[0.33113432,0.75957322]$} \\
\hline Xu 2014 & 0.79082412 & {$[0.55961406,1.0220342]$} \\
\hline Combined & 0.52743134 & {$[0.32883657,0.72602611]$} \\
\hline
\end{tabular}

\section{Schirmer I test 1 month postoperatively}

The data of Schirmer I test 1 month postoperatively were available from 5 studies [14-17, 19], and the forest plot was shown in Fig. 6 . A total of 186 eyes were randomly allocated to the LSCT group and 182 to the AMT group. The heterogeneity test was conducted, showing heterogeneity among the selected 5 studies ( $I^{2}=82 \%, P \otimes 0.1$, fixed effect) (Fig. 6a). A sensitivity analysis was conducted for the 5 studies, and it was found that the heterogeneity came from the study of Chen 2018 (Table 4). Therefore, the study of Chen 2018 was removed. The heterogeneity test was performed again, and the result showed low heterogeneity among the remaining 4 studies $\left(I^{2}=50 \%, P=0.11\right.$, fixed effect) (Fig. $\left.6 \mathrm{~b}\right)$. Finally, the fixed effect model was employed for the study. The wetting Schirmer paper strip's measured length was increased slightly in the LSCT group compared with the AMT group. However, the difference was not significant (pooled MD $=0.05,95 \% \mathrm{Cl}:-0.41,0.51, P=0.82$, fixed effect) (Fig. 6b). 
Table 4

The sensitivity analysis of Schirmer I test 1 month

\begin{tabular}{|lll|}
\hline \multicolumn{3}{|c|}{ postoperatively between the LSCT group and the AMT group } \\
\hline Study omitted & Estimate & [95\% Conf. Interval] \\
\hline Bai 2017 & 0.96717227 & {$[0.85120273,1.0831418]$} \\
\hline Chen 2018 & 0.05452737 & {$[-0.4051609,0.51421565]$} \\
\hline Dai 2013 & 1.002733 & {$[0.88500863,1.1204573]$} \\
\hline Hai 2019 & 0.96586663 & {$[0.84921741,1.0825158]$} \\
\hline Li 2015 & 0.95841461 & {$[0.84213263,1.0746967]$} \\
\hline Combined & 0.95881356 & {$[0.84309065,1.0745365]$} \\
\hline
\end{tabular}

\section{Schirmer I test $\mathbf{3}$ months postoperatively}

The data of Schirmer I test 3 months postoperatively were available from 5 studies [14, 16-19], and the forest plot was shown in Fig. 7 . A pooled total of 166 eyes were randomly allocated to the LSCT group and 162 to the AMT group. According to the heterogeneity test, it was shown that there was significant heterogeneity among the 5 studies $\left(I^{2}=82 \%, P \otimes 0.1\right.$, fixed effect) (Fig. 7a). After conducting the sensitivity analysis, we found that when we excluded the study of Dai 2013 (Table 5), there was no heterogeneity among the remaining 4 studies $\left(I^{2}=16 \%, P=0.31\right.$, fixed effect) (Fig. 7b). The increased measured length of wetting Schirmer paper strip in the LSCT group compared to the AMT group. The difference was statistically significant (pooled MD $=1.41,95 \% \mathrm{Cl}: 0.81,2.02$, $P \otimes 0.05$, fixed effect) (Fig. 7b).

Table 5

The sensitivity analysis of Schirmer I test 3 months

\begin{tabular}{|c|c|c|}
\hline Study omitted & Estimate & [95\% Conf. Interval] \\
\hline Bai 2017 & 0.44222012 & {$[0.0229817,0.86145854]$} \\
\hline Dai 2013 & 1.4144325 & [0.8135156,2.0153494] \\
\hline Hai 2019 & 0.14910085 & {$[-0.29784036,0.59604204]$} \\
\hline Li 2020 & 0.26982006 & {$[-0.16024075,0.6998809]$} \\
\hline Li 2015 & 0.42733917 & {$[0.00223994,0.85243839]$} \\
\hline Combined & 0.45084489 & {$[0.04600235,0.85568742]$} \\
\hline
\end{tabular}

\section{CFS 1 month postoperatively}

Two studies were conducted in the meta-analysis of CFS outcomes $[15,16]$. Seventy eyes were randomly allocated to the LSCT group and 70 to the AMT group. Compared with the AMT group, the CFS score was decreased in the LSCT group, but there was no statistical difference (pooled MD=-0.49, 95\% Cl:-1.29,0.31, $P=0.23$, random effect) (Fig. 8).

\section{Publication Bias}

The shape of the funnel plot revealed that the data of each outcome measure were symmetrical (Fig. 9), which was confirmed by the Begg's and Egger's tests (all $P \otimes 0.05$ ). Indicating that the results of each outcome measure in our meta-analysis did not show a publication bias.

\section{Discussion}

Pterygium is a common frequently ocular surface disease with a global prevalence of 12\% [21]. Besides, pterygium is a multifactorial degenerative disease [1]. However, the etiopathology remains unclear. One of the primary risk factors of pterygium is exposure to ultraviolet light. The most effective method for the treatment of this disorder is surgery. LSCT or AMT is commonly used for pterygium surgery. LSCT is better in terms of esthetic appearance and has less recurrence rate than AMT [22]. Of course, AMT also has its advantages, which can be beneficial in patients with ocular surface reconstruction, such as extensive conjunctival scarring and chemical injury or those who may require future glaucoma surgery $[1,10]$. A previous study showed that regardless of the surgical approach, the tear film stability of patients after pterygium surgery is improved to varying degrees [13]. However, because the degree of tear film stability improvement by the above two transplant means still showed conflicting results [14-20], we conducted this meta-analysis to provide a more robust and accurate estimate of our study.

The present study elicited four main findings through subjective tests (OSDI) and objective tests (BUT, Schirmer I test and CFS score). First, the extracted data from 7 studies revealed decreased DED symptoms (based on the OSDI) in the LSCT group compared to the AMT group (MD=-5.16, 95\%Cl:-6.48 -3.85, $P \otimes 0.05$ ). Second, Improved tear film stability 1 or 3 months postoperatively (based on the BUT) in the LSCT group compared with the AMT group. However, none of the 
differences were significant ( 1 month: $\mathrm{MD}=0.30,95 \% \mathrm{Cl}:-0.66,1.26, P=0.54 ; 3$ months: $\mathrm{MD}=1.30,95 \% \mathrm{Cl}:-0.13,2.72, P=0.07$ ). Third, Increased tear production 1 or 3 months postoperatively (based on the Schirmer I test) in the LSCT group compared with the AMT group. Among them, the results 1 month postoperatively were not significant $(\mathrm{MD}=0.05,95 \% \mathrm{Cl}:-0.41,0.51, P=0.82)$, and the results 3 months postoperatively were statistically significant $(\mathrm{MD}=1.41$, $95 \% \mathrm{Cl}: 0.81,2.02, P \otimes 0.05)$. Finally, The LSCT group tended to show a decreased degree of DED symptoms (based on the CFS) compared with the AMT group. However, the difference was not significant (MD=-0.49, 95\% Cl:-1.29,0.31, $P=0.23)$.

Tear film stability is primarily assessed by BUT. Besides, OSDI, Schirmer I test and CFS score are also available for reference. As a subjective method, OSDI is widely used to evaluate DED in clinical trials, measuring the frequency of symptom appearance, environmental conditions, and quality of life-related to vision [23]. Although the score is produced subjectively, it is well-known that it has reliability and reproducibility compared with other objective tests [24]. Decreased tear film stability can induce symptoms of DED. Therefore, subjective measures such as OSDI may be important indicators for evaluating tear film stability. The BUT is the most commonly used clinical diagnostic test for tear film stability [25]. It measures the time interval between the complete blink and the appearance of the first break in the tear film [23]. The Schirmer I test is a commonly used method for measuring tear production [23]. Tear osmolarity is a function of tear secretion and tear evaporation [26]. Studies have shown that lower tear production can lead to higher tear osmolarity levels [27]. And there is an interconnection between hyperosmolarity and tear instability [28]. Therefore, Schirmer I test can be used as an indirect assessment indicator of tear film stability. CFS score is an informative marker of severe DED. However, patients with mild/moderate DED showed a poor correlation with CFS score [29]. Thus, it may be poorly linked with mild tear film instability.

This study has several limitations. First, most of the included studies had a relatively small sample size. It may be caused by the search was restricted to articles written in English or Chinese, so some compliant studies not written in English or Chinese may be excluded. Second, our meta-analysis involved only a Chinese population. One possible reason was that there were few studies in other countries on improving tear film stability after pterygium surgery comparing LSCT with AMT.

In conclusion, our study showed that the OSDI and Schirmer I test 3 months postoperatively of the LSCT group were better than those of the AMT group with statistical significance. We can preliminarily suggest that tear film stability after primary pterygium excision combined with LSCT is superior to AMT. Further studies with larger sample sizes, well-designed RCTs, and longer follow-up are needed to confirm the results reported in our meta-analysis.

\section{Declarations Funding}

This work was supported by the Key Research and Development Program of Shandong Province, China(No. 2018GSF118081).

\section{Conflict of Interest Statement}

No conflicting relationship of interest exists for any author.

\section{Data availability statement}

The datasets generated during and/or analysed during the current study are available from the corresponding author on reasonable request.

\section{References}

1. Chu WK, Choi HL, Bhat AK et al (2020) Pterygium: new insights. Eye (Lond) 34:1047-1050

2. Clearfield E, Muthappan V, Wang X et al (2016) Conjunctival autograft for pterygium. Cochrane Database Syst Rev 2:CD011349

3. Ye F, Zhou F, Xia Y et al (2017) Evaluation of meibomian gland and tear film changes in patients with pterygium. Indian J Ophthalmol 65:233-237

4. Safarzadeh M, Heidari S, Azizzadeh P et al (2019) Comparative Assessment of Tear Function Tests, Tear Osmolarity, and Conjunctival Impression Cytology between Patients with Pterygium and Healthy Eyes. J Ophthalmic Vis Res 14:11-17

5. Clearfield E, Hawkins BS, Kuo IC (2017) Conjunctival autograft versus amniotic membrane transplantation for treatment of pterygium: findings from a Cochrane Systematic Review. Am J Ophthalmol 182:8-17

6. Akbari M, Soltani-Moghadam R, Elmi R et al (2017) Comparison of free conjunctival autograft versus amniotic membrane transplantation for pterygium surgery. J Curr Ophthalmol 29:282-286

7. Singh V, Tiwari A, Kethiri AR et al (2021) Current perspectives of limbal-derived stem cells and its application in ocular surface regeneration and limbal stem cell transplantation. Stem Cells Transl Med 1-8

8. Yin J, Jurkunas U (2018) Limbal Stem Cell Transplantation and Complications. Semin Ophthalmol 33:134-141

9. Sippel KC, Ma JJ, Foster CS (2001) Amniotic membrane surgery. Curr Opin Ophthalmol 12:269-281

10. Mamede AC, Carvalho MJ, Abrantes AM et al (2012) Amniotic membrane: from structure and functions to clinical applications. Cell Tissue Res 349:447458

11. Willcox MDP, Argüeso P, Georgiev GA et al (2017) TFOS DEWS II Tear Film Report. Ocul Surf 15:366-403

12. Ozsutcu M, Arslan B, Erdur SK et al (2014) Tear Osmolarity and Tear Film Parameters in Patients With Unilateral Pterygium. Cornea 33:1174-1178

Page $7 / 14$ 
13. Linaburg T, Choi D, Bunya VY et al (2021) Systematic Review: Effects of Pterygium and Pingueculum on the Ocular Surface and Efficacy of Surgical Excision. Cornea 40:258-267

14. Bai ZG (2017) Study on the changes of tear film function by excision of pterygium combined with second-generation amniotic membrane transplantation (Chinese). Dissertation, Inner Mongolia University For The Nationalities

15. Chen GS (2018) Analysis of curative effect and tear film stability of pterygium treated by different surgical methods. Shenzhen Journal of Integrated Traditional Chinese Western Medicine (Chinese) 28:159-161

16. Dai J, Li DP, Tai CP (2013) Clinical analysis of different surgical methods on tear function in patients with pterygium. Journal of Practical Preventing Blind (Chinese) 8:122-124

17. Hai O, Liu F, Li P (2019) Effects of different surgical methods of pterygium on the function of tear film. Int Eye Sci (Chinese) 19:1439-1441

18. Li K, Niu LC (2020) Effect of pterygium excision combined with limbal stem cell transplantation on postoperative tear film function. Diet Health (Chinese) 7:27-28

19. Li Q, Guo JX (2015) Clinical observation of the dry eye after the different surgical methods for pterygium. Chin J Ophthalmology Otorhinolaryngology (Chinese) 15:406-408

20. Xu B, Zhang MC, Gao L (2014) Limbal epithelial autograft transplantation and amniotic membrane transplantation combined with pterygium excision for primary pterygium. Int Eye Sci (Chinese) 14:2019-2021

21. Rezvan F, Khabazkhoob M, Hooshmand E et al (2018) Prevalence and risk factors of pterygium: a systematic review and meta-analysis. Surv Ophthalmol 63:719-735

22. Hussain SA, Haider Shaheen K, Ullah MS et al (2020) Recurrence of Pterygium after Pterygium Excision with Stem Cell Graft and Amniotic Membrane Graft: A Comparison. Cureus 12:e6535

23. Wolffsohn JS, Arita R, Chalmers R et al (2017) TFOS DEWS II Diagnostic Methodology report. Ocul Surf 15:539-574

24. Nichols KK (2006) Patient-reported symptoms in dry eye disease. Ocul Surf 4:137-145

25. Methodologies to diagnose and monitor dry eye disease (2007) Report of the Diagnostic Methodology Subcommittee of the International Dry Eye WorkShop. Ocul Surf 5:108-152

26. Ozsutcu M, Arslan B, Erdur SK et al (2014) Tear Osmolarity and Tear Film Parameters in Patients With Unilateral Pterygium. Cornea 33:1174-1178

27. Wanzeler ACV, Barbosa IAF, Duarte B et al (2019) Impact of pterygium on the ocular surface and meibomian glands. PLoS One 14:e0213956

28. Liu H, Begley C, Chen M et al (2009) A link between tear instability and hyperosmolarity in dry eye. Invest Ophthalmol Vis Sci 50:3671-3679

29. Sullivan BD, Whitmer D, Nichols KK et al (2010) An objective approach to dry eye disease severity. Invest Ophthalmol Vis Sci 51:6125-6130

\section{Figures}




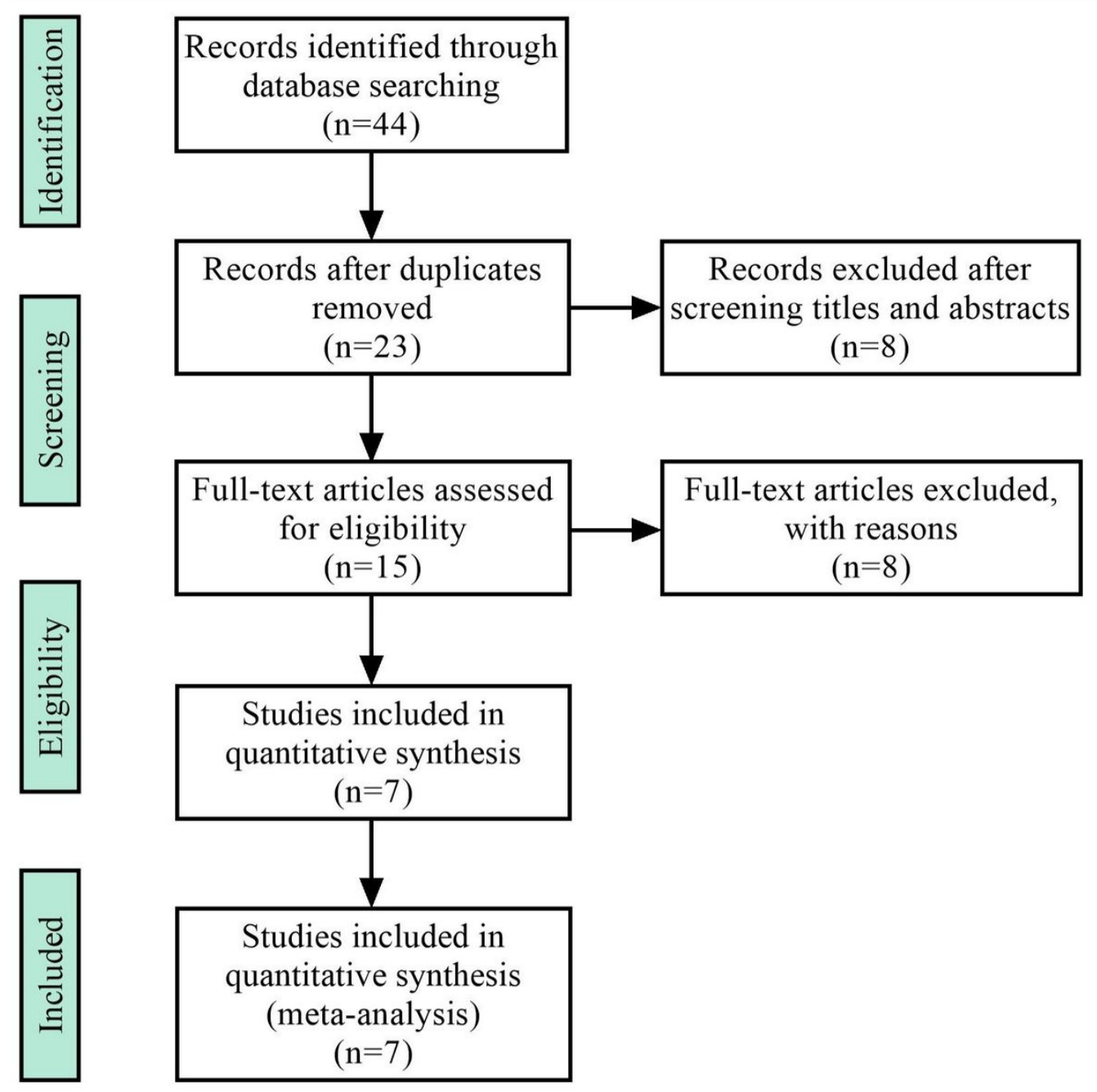

Figure 1

Flow diagram of studies selection 
a

b

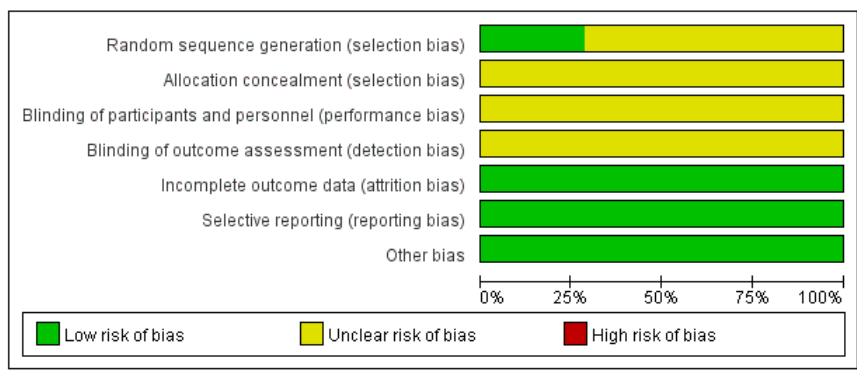

\begin{tabular}{|c|c|c|c|c|c|c|c|}
\hline & 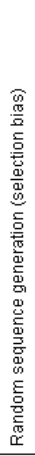 & 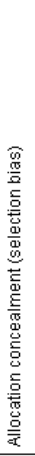 & 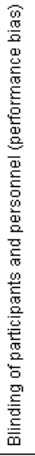 & 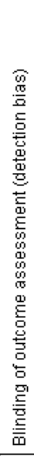 & 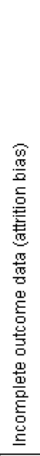 & 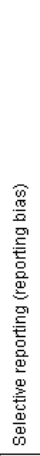 & 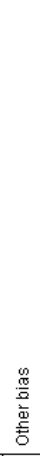 \\
\hline Bai 2017 & ? & ? & $?$ & $?$ & ๑ & ๑ & $\odot$ \\
\hline Chen 2018 & ? & ? & ? & $?$ & $\odot$ & $\odot$ & ๑ \\
\hline Dai 2013 & $?$ & ? & ? & $?$ & $\odot$ & $\odot$ & $\odot$ \\
\hline Hai 2019 & $?$ & ? & $?$ & $?$ & $\odot$ & $\odot$ & $\odot$ \\
\hline Li 2015 & † & $?$ & $?$ & $?$ & $\odot$ & $\odot$ & $\odot$ \\
\hline Li 2020 & † & $?$ & $?$ & $?$ & ๑ & $\odot$ & ๑ \\
\hline Хи 2014 & ? & $?$ & $?$ & $?$ & $\odot$ & 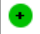 & ๑ \\
\hline
\end{tabular}

\section{Figure 2}

Cochrane risk of bias graph and summary a: Risk of bias graph: authors' judgments about each risk of bias item presented as percentages across all included studies; b: Risk of bias summary: authors' judgments about each risk of bias item for each included study

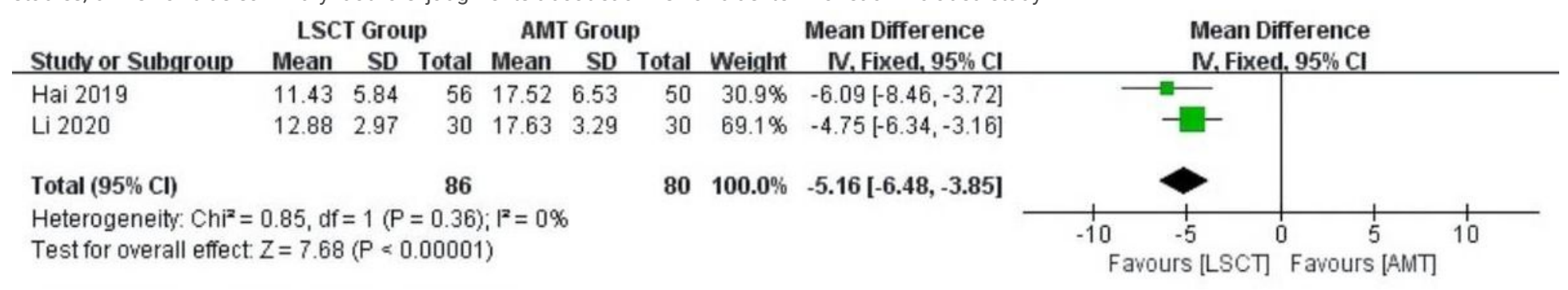

\section{Figure 3}

Forest plot of OSDI 3 months postoperatively between the LSCT group and the AMT group 


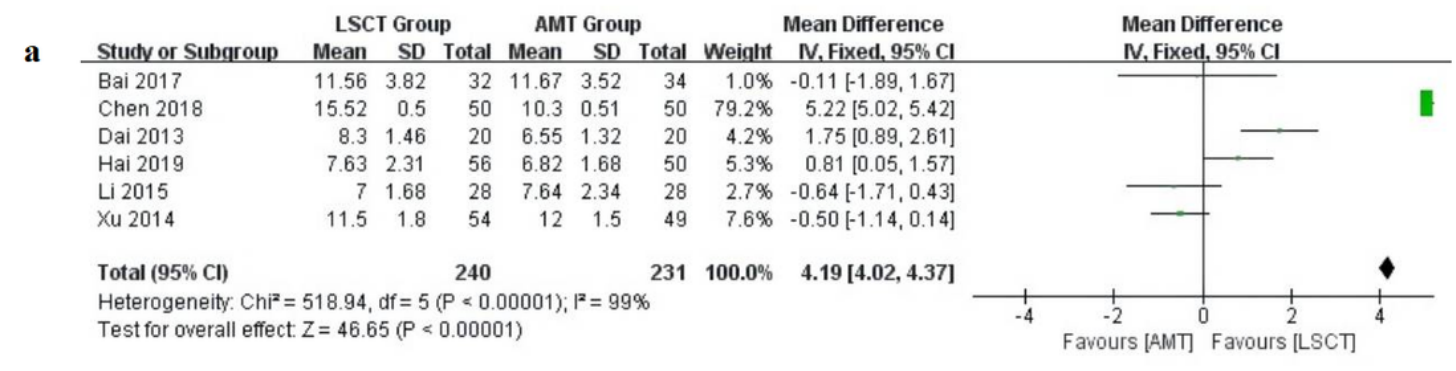

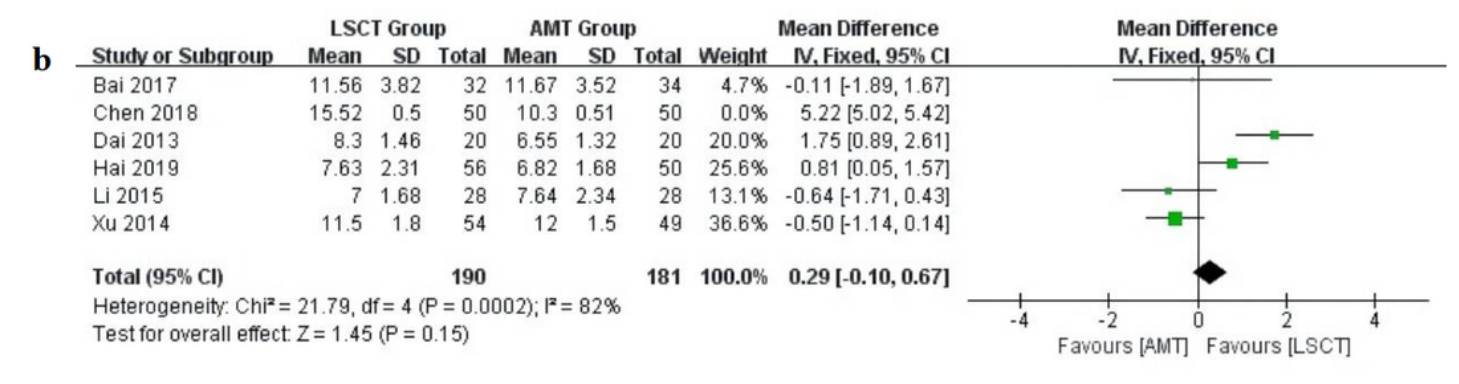

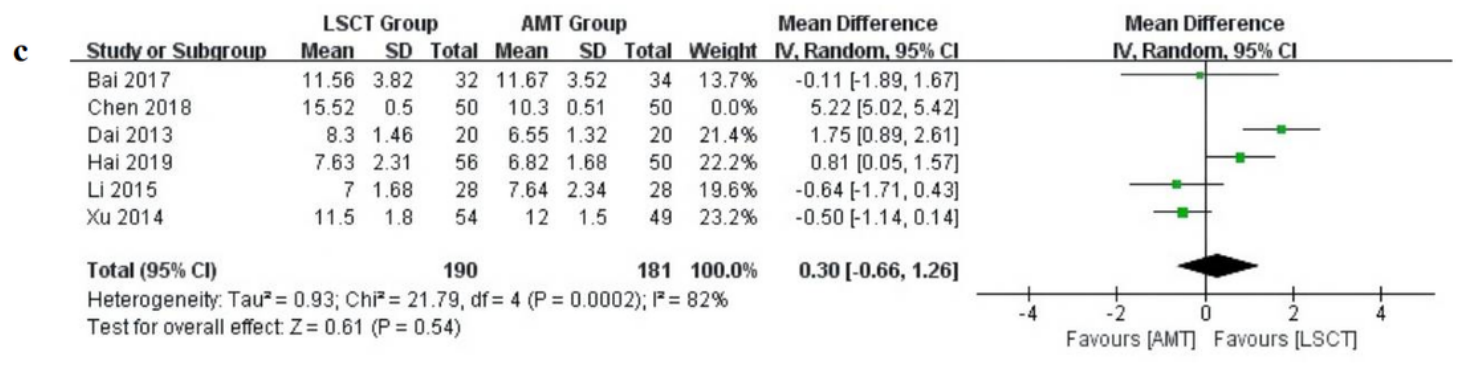

\section{Figure 4}

Forest plot of BUT 1 month postoperatively between the LSCT group and the AMT group a: Results based on the fixed effect model in 6 studies; b: Results based on the fixed effect model in 5 studies; c: Results based on the random effect model in 5 studies 


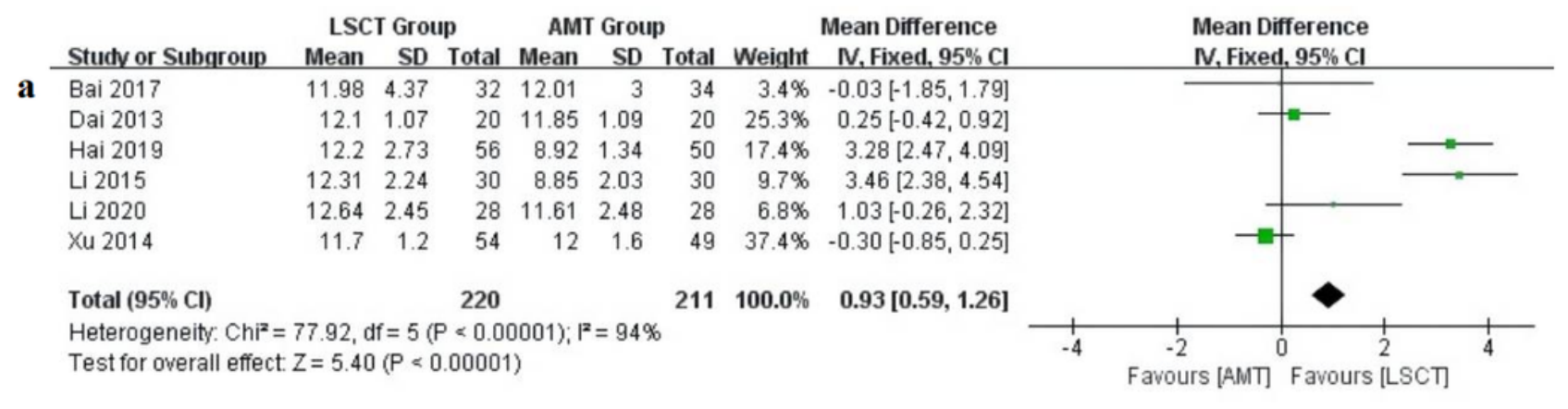

b

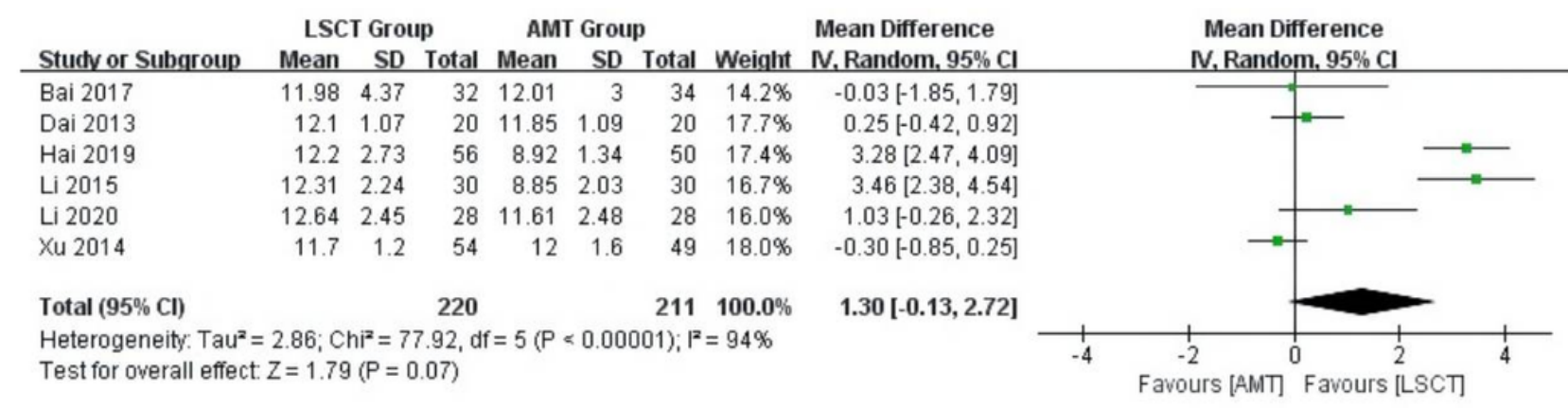

Figure 5

Forest plot of BUT 3 months postoperatively between the LSCT group and the AMT group a: Results based on the fixed effect model in 6 studies; b: Results based on the random effect model in 5 studies

a

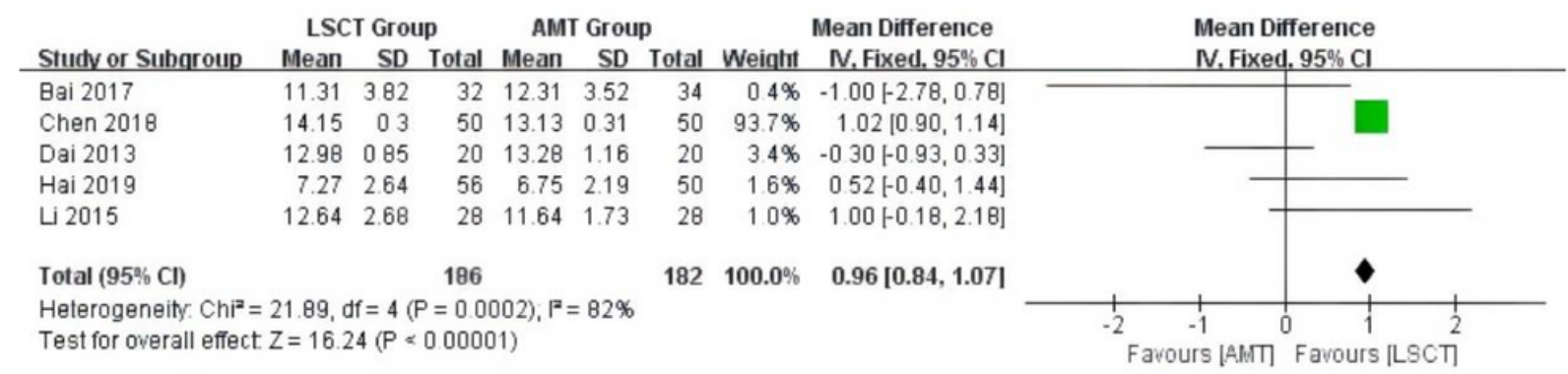

b

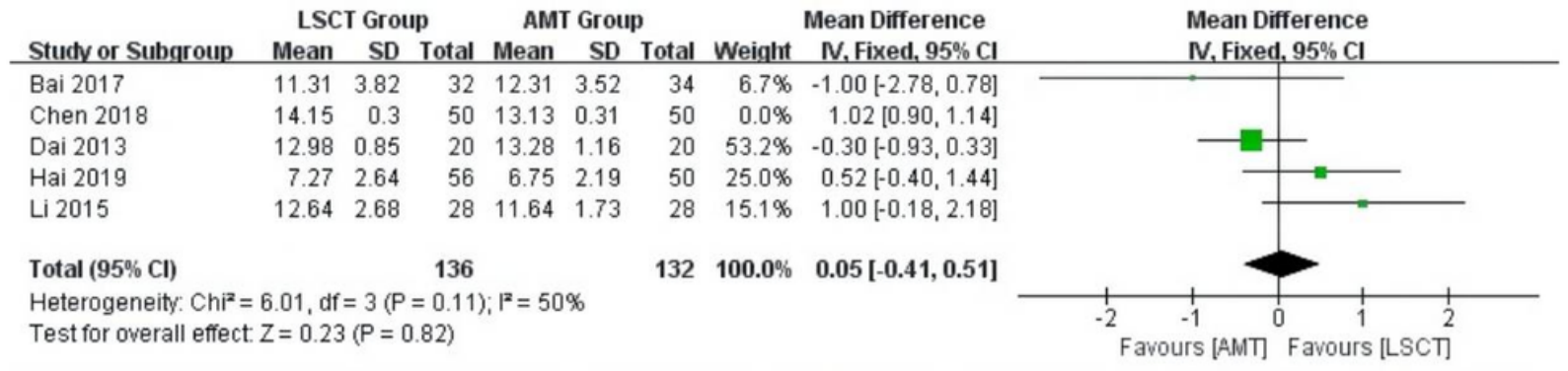

Figure 6 
Forest plot of Schirmer I test 1 month postoperatively between the LSCT group and the AMT group a: Results based on the fixed effect model in 5 studies; b: Results based on the fixed effect model in 4 studies

a

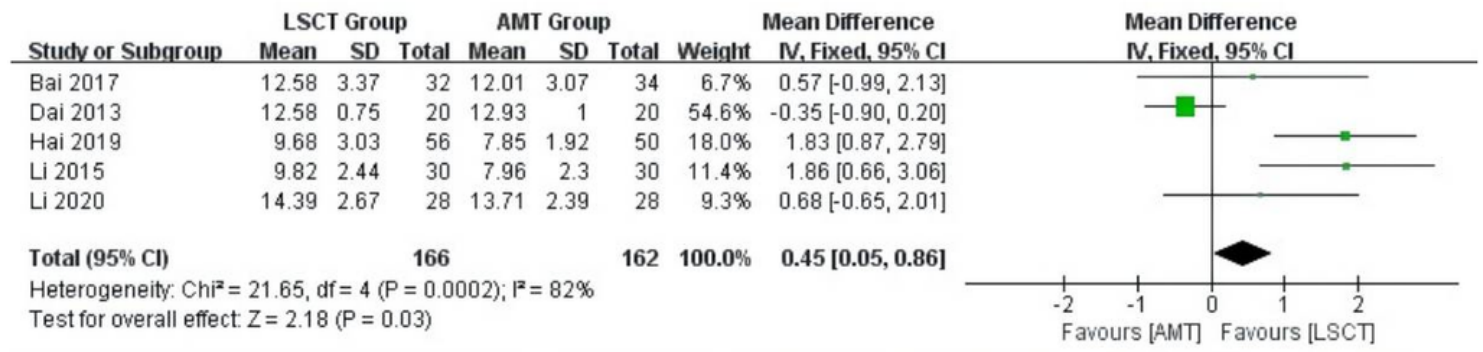

b

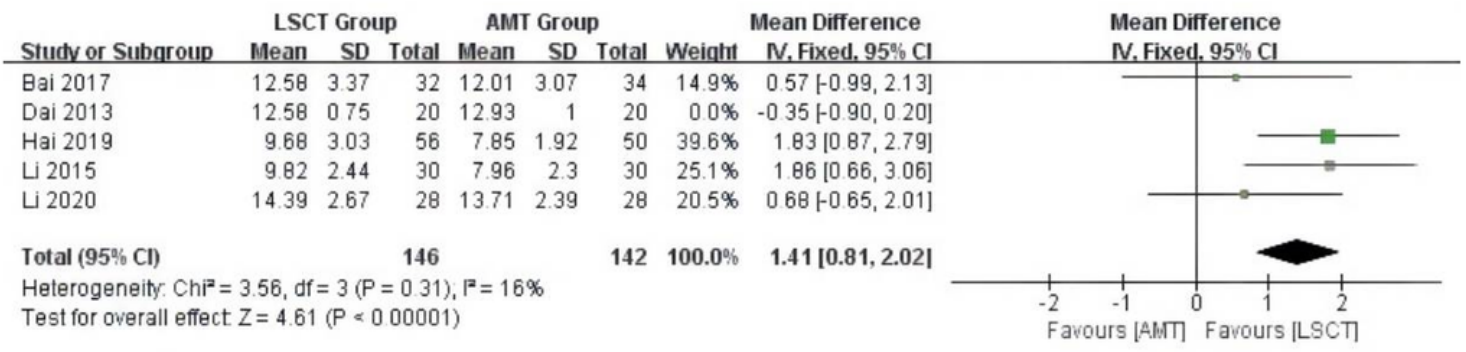

c

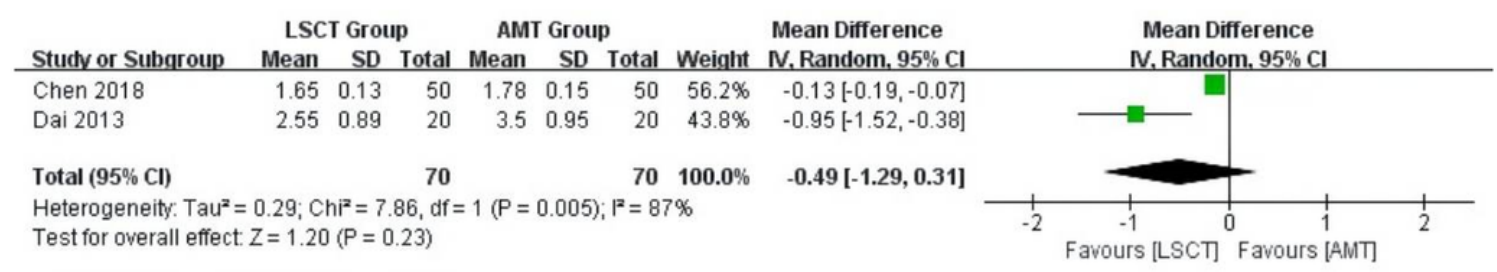

Figure 7

Forest plot of Schirmer I test 3 months postoperatively between the LSCT group and the AMT group a: Results based on the fixed effect model in 5 studies; b: Results based on the fixed effect model in 4 studies

\begin{tabular}{|c|c|c|c|c|c|c|c|c|c|c|c|c|}
\hline \multirow[b]{2}{*}{ Studv or Subqroup } & \multicolumn{3}{|c|}{ LSCT Group } & \multicolumn{3}{|c|}{ AMT Group } & \multirow{2}{*}{\multicolumn{2}{|c|}{$\begin{array}{cl} & \text { Mean Difference } \\
\text { Weight } & \text { N, Random, 95\% Cl }\end{array}$}} & \multirow{2}{*}{\multicolumn{3}{|c|}{$\begin{array}{c}\text { Mean Difference } \\
\text { IV, Random, } 95 \% \mathrm{Cl}\end{array}$}} & \\
\hline & Mean & SD & Total & Mean & SD & Total & & & & & & \\
\hline Chen 2018 & 1.65 & 0.13 & 50 & 1.78 & 0.15 & 50 & $56.2 \%$ & $-0.13[-0.19,-0.07]$ & & I & & \\
\hline Dai 2013 & 2.55 & 0.89 & 20 & 3.5 & 0.95 & 20 & $43.8 \%$ & $-0.95[-1.52,-0.38]$ & & & & \\
\hline Total $(95 \% \mathrm{Cl})$ & & & 70 & & & 70 & $100.0 \%$ & $-0.49[-1.29,0.31]$ & & & & \\
\hline $\begin{array}{l}\text { Heterogeneity: Tauz } \\
\text { Test for overall effec }\end{array}$ & $\begin{array}{l}0.29 ; \mathrm{Cr} \\
\mathrm{Z}=1.20\end{array}$ & $\begin{array}{l}\mathrm{i}^{2}=7 \\
(\mathrm{P}=0\end{array}$ & $\begin{array}{l}86, \mathrm{df}= \\
\text { 23) }\end{array}$ & $1(P=$ & $0.005)$ & $F^{2}=8$ & & & -2 & $\begin{array}{ll}-1 & \\
\text { urs [LSCT] }\end{array}$ & Favours [A & 2 \\
\hline
\end{tabular}

Figure 8

Forest plot of CFS 1 month postoperatively between the LSCT group and the AMT group 

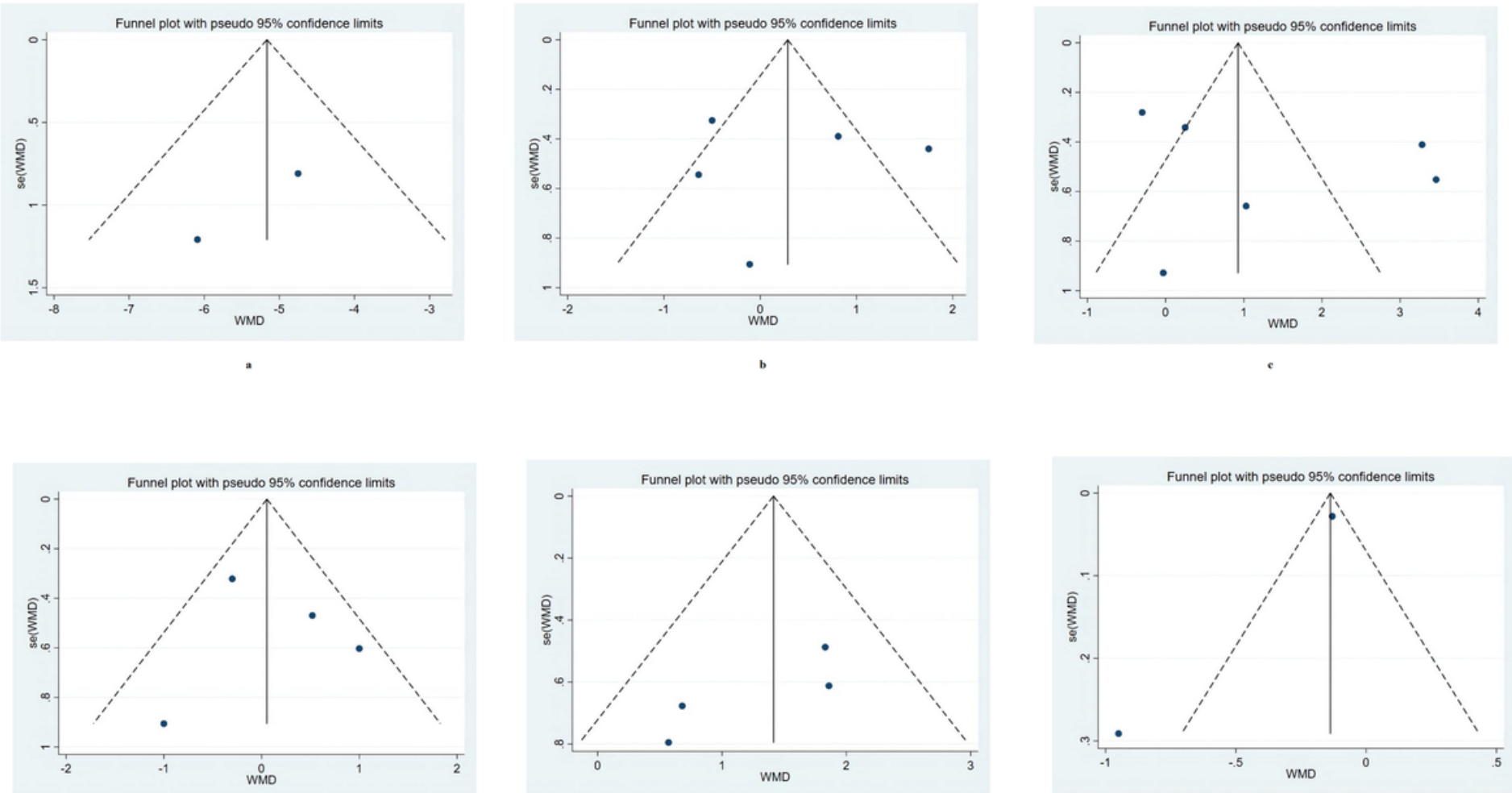

\section{Figure 9}

Funnel plot of each outcome measure between the LSCT group and the AMT group a: Results of OSDI 3 months postoperatively; b: Results of BUT 1 month postoperatively; c: Results of BUT 3 months postoperatively; d: Results of Schirmer I test 1 month postoperatively; e: Results of Schirmer I test 3 months postoperatively; f: Results of CFS 1 month postoperatively 